\title{
A multi-responsive coumarin-benzothiazole fluorescent probe for selective detection of biological thiols and hydrazine
}

\author{
Kangni Chen, Yanbo Li, Jinyan Shang and Heping Li ${ }^{*}$ (i)
}

\begin{abstract}
Biothiols play important roles in various physiological and biological processes, which closely related to many diseases. Hydrazine is widely used in the chemical industry, but it is harmful to humans and animals. Therefore, it is very important to develop a fluorescent probe that can simultaneously detect biological thiols and hydrazine. In this work, a new fluorescent probe (2E,4Z)-2-(benzo[d] thiazol-2-yl)-5-chloro-5-(7-(diethylamino)-2-oxo-2H-chromen-3-yl)penta2,4-dienenitrile $(B C D)$ was synthesized by integrating coumarin and benzothiazole acetonitrile. Featured with four binding sites and different bonding mechanism between probe with biothiols and hydrazine, this probe exhibited fluorescent turn-on for distinguishing Cys, Hcy, GSH and hydrazine with 760-, 8-, 6- and 637-fold fluorescent intensity increase at 502, 479, 476 and $458 \mathrm{~nm}$, respectively, through different excitation wavelengths. Research on the effect of $\mathrm{pH}$ on the fluorescent performance of BCD shows that the probe exhibits superior stability in a weakly alkaline to weakly acidic environment, which will facilitate the detection of biological thiols or hydrazine hydrate by BCD. Selectivity studies have shown that the probe has high specificity to biological thiols and hydrazine, which is of great significance to the application of BCD.
\end{abstract}

Keywords: Biological thiols, Hydrazine, Coumarin, Fluorescent probe

\section{Introduction}

Cysteine (Cys), homocysteine (Hcy) and glutathione (GSH) are three very important biological thiols, which play important roles in various physiological and biological processes. Therefore, they are closely related to many diseases. Cys participates in the regulation of human intestinal function, lipid metabolism and other processes (Jung et al. 2013). Cys deficiency can cause slow growth in children, hair loss, edema, lethargy, liver damage, muscle and fat loss, skin lesions and weakness (Shahrokhian 2001; Sachdev 2004). The lack of Hcy will increase the risk of vascular disease, and it will directly lead to brain atrophy, cognitive impairment and Alzheimer's disease

\footnotetext{
*Correspondence: lihepinghn@126.com

School of Chemistry and Food Engineering, Changsha University

of Science and Technology, No. 960, Wanjiali South Road, Tianxin District,

Changsha City 410114, Hunan Province, China
}

(Yeun 1998). It has been proven to be an independent risk factor for cardiovascular disease in the general population (Wu et al. 2012). GSH is the redox center of the cell. GSH is also directly involved in the production of signal molecules (such as $\mathrm{H}_{2} \mathrm{~S}$ ), the process of protein functionalization and some other processes, and it is a key part of gene regulation and signal transduction in the cell (Franco et al. 2007; Townsend et al. 2003). There is a causal relationship between GSH metabolism and diseases such as cancer, neurodegenerative diseases, cystic fibrosis, human immunodeficiency diseases and aging (Seshadri et al. 2002). GSH levels in patients with AIDS and Alzheimer's disease are low (Borges-Santos et al. 2012; Puertas et al. 2012), and GSH levels in patients with neurodegenerative diseases are on the rise (Baillet et al. 2010). The imbalance of GSH synthesis is the cause of many pathological conditions, including diabetes, pulmonary fibrosis, and endotoxemia (Townsend et al. 2003; 
$\mathrm{Lu}$ 2009). Therefore, the detection of these three biological thiols in cells, tissues and living bodies is of great significance to their physiology and pathology research.

Hydrazine $\left(\mathrm{N}_{2} \mathrm{H}_{4}\right)$ is an important biochemical reagent, which can be used as a metal corrosion inhibitor (Cruz Vieira et al. 2002), antibacterial drugs (Balsamo et al. 1983), plant growth regulators (Huffman et al. 1968), hydrazine fuel cell (Serov and Kwak 2010), and be used in rocket propulsion Propellant system (Zelnick Sanford et al. 2003; Mo et al. 2000). It is widely used in various chemical industries. However, as a volatile and toxic compound, hydrazine can cause serious damage to human bodies and animal organs (such as the central nervous system and respiratory system) (Garrod et al. 2005). The US Environmental Protection Agency stipulates that the concentration of hydrazine hydrate in drinking water shall not be higher than $10 \mathrm{ppb}$ (Virji et al. 2005). Therefore, the specific detection of trace hydrazine hydrate is of great significance. Fluorescent probes are currently the preferred choice for the detection of biological thiols due to their simple structure, high sensitivity and real-time visualization of physiological processes. At present, there are a large number of fluorescent probes that can specifically recognize Cys/Hcy or GSH. Based on an improved aromatic substitution rearrangement strategy, He et al. developed a new proportional fluorescence probe (CouSBD-Cl) is based on the coumarin-sulfonylbenzoxadiazole platform. It can specifically detect Cys. However, 4-chloro-7-chlorosulfonyl-2,1,3-benzoxadiazole, the raw material for synthetic probes, is relatively expensive ( $\mathrm{He}$ et al. 2017). Zou et al. designed a two-photon fluorescent probe Cou-Br based on coumarin derivatives to detect GSH in living cells, mouse models, and clinical specimens. However, the maximum absorption wavelength of the probe is very small before and after adding GSH, and the existence of Cys/Hcy has some influence on the detection (Zou et al. 2020). Due to the similarity in the nature and structure of Cys/Hcy and GSH, it is still a big challenge to distinguish these three biothiols. Therefore, there is an urgent need to develop new fluorescent probes to simultaneously detect these three biological thiols. Due to the difference in their spatial structure, they may combine with different reaction sites to generate different products, resulting in changes in the color and fluorescence signal of the system. Nowadays, the use of multi-site fluorescent probes to detect and distinguish biological thiols has become a trend. The multi-site fluorescent probe designed by Xiong et al. can detect Cys, Hcy and GSH at the same time, and the changes before and after the reaction are obvious, which can better distinguish Cys, Hcy and GSH, but the presence of $\mathrm{HSO}_{3}{ }^{-}$ and $\mathrm{S}^{2-}$ will significantly affect its detection Therefore, the specificity of the probe is not high enough, which affects its practical application (Xiong et al. 2019). Therefore, it is particularly important to design and synthesize a new type of multi-site fluorescent probe with high sensitivity, strong specificity, and capable of simultaneously detecting and distinguishing Cys, Hcy and GSH. Wu et al. reported a dual analyte-responsive fluorescent probe CMCA, which can detect hydrazine and bisulfite in different fluorescence emission channels, and was successfully applied to the quantitative determination of hydrazine and subsulfite in living cells and environmental water samples (Wu et al. 2018).

In this work, a multi-site fluorescent probe $(2 \mathrm{E}, 4 \mathrm{Z})$ 2-(benzo[d]thiazol-2-yl)-5-chloro-5-(7-(diethylamino)2-oxo-2H-chromen-3-yl)penta-2,4-dienenitrile (BCD) based on coumarin derivatives was constructed and synthesized (Scheme 1). The synthesis steps are simple, the raw materials are easily available, and the purpose of simultaneously detecting and distinguishing Cys, Hcy and GSH can be achieved. At the same time, it can detect trace amounts of hydrazine hydrate in different fluorescence channels.

\section{Materials}

Unless otherwise stated, all reagents used were purchased from commercial suppliers without further purification. The corresponding chemical reagents were purchased from Macleans or Aladdin, USA; the corresponding solvents were purchased from Shanghai Titan Technology Co., Ltd. The water used throughout the study was deionized water. Dissolve a certain amount of probe $\mathrm{BCD}$ in DMF to obtain a $2 \mathrm{mM}$ probe stock solution. Prepare amino acids with deionized water: threonine (Thr), isoleucine (Ile), histidine (His), glutamine acid (Glu), alanine (Ala), glycine (Gly), serine (Ser), methionine (Met), phenylalanine (Phe), proline (Pro), leucine (Leu), aspartic acid (Asn), lysine (Lys), valine (Val); anions: $\mathrm{HSO}_{3}{ }^{-}$, $\mathrm{SO}_{4}{ }^{2-}, \mathrm{ClO}^{-}, \mathrm{I}^{-}, \mathrm{NO}_{3}{ }^{-}$; cations: $\mathrm{Na}^{+}, \mathrm{Mg}^{2+}, \mathrm{Ca}^{2+}, \mathrm{Ag}^{+}$, $\mathrm{Al}^{3+}, \mathrm{K}^{+}, \mathrm{Mn}^{2+}, \mathrm{Zn}^{2+}, \mathrm{Ni}^{2+}, \mathrm{Cd}^{2+}, \mathrm{Ba}^{2+}, \mathrm{Co}^{2+}$; triethylamine, piperidine aqueous solution $(10 \mathrm{mM})$. For fluorescence testing, the excitation and emission wavelength slits are both set to $2.5 \mathrm{~nm}$.

\section{Instrumentation}

Ultraviolet absorption spectrum (UV-Vis) was measured with an ultraviolet-visible spectrophotometer (TU-1901, Beijing). F-7000 fluorescence spectrophotometer (Hitachi, Japan) was used to record the fluorescence emission spectrum. Using TMS as an internal reference, ${ }^{1} \mathrm{HNMR}$ and ${ }^{13} \mathrm{CNMR}$ spectra were recorded on a Varian INOVA-400 nuclear magnetic resonance spectrometer. High-resolution spectral analysis (HRMS) was performed on the LTQ Orbitrap XL mass spectrometer. 
<smiles>CCOC(=O)CC(C)=O</smiles><smiles>CCN(CC)c1ccc2cc(C(C)=O)c(=O)oc2c1</smiles><smiles>CO[C@H](C)CN=C(C#N)CCC#N</smiles><smiles>CCN(CC)c1ccc2cc(/C(Cl)=C/C=O)c(=O)oc2c1</smiles>

2<smiles>N#CCc1nc2ccccc2s1</smiles>

3<smiles>CCN(CCC(C)CCl)c1ccc2cc(/C(Cl)=C/C=C(\C)c3nc4ccccc4s3)c(=O)oc2c1</smiles>

Scheme 1 Synthesis of BCD

Use Mettler-Toledo Delta320 $\mathrm{pH}$ meter to measure the $\mathrm{pH}$ value. Other instruments include vertical rotary steamer, SHB-III water circulation multi-purpose vacuum pump.

\section{Synthesis}

Synthesis of compound 1: The target compound was synthesized according to the known literature (Debnath et al. 2015). 4-(Diethylamino)-2-hydroxybenzaldehyde $(2.90 \mathrm{~g}, 15.01 \mathrm{mmol})$ was dissolved in $40 \mathrm{~mL}$ of absolute ethanol, then add ethyl acetoacetate $(2.30 \mathrm{~mL}, 2.34 \mathrm{~g}$, $17.98 \mathrm{mmol}$ ) and three drops piperidine. The mixed solution was stirred and refluxed for $12 \mathrm{~h}$. After the reaction was completed, it was cooled to room temperature and vacuum-filtered to obtain a filter cake. The filter cake was recrystallized with absolute ethanol to obtain $2.93 \mathrm{~g}$ of yellow powder with a yield of $75.22 \%$.

Synthesis of compound 2: Synthesized according to references (Chen et al. 2018; El-Kazak et al. 2019) and made appropriate improvements. In a $100-\mathrm{mL}$ round-bottom flask, cool an anhydrous $\mathrm{N}, \mathrm{N}$-dimethylformamide $(5.00 \mathrm{~mL}, 4.75 \mathrm{~g}, 65.00 \mathrm{mmol})$ solution to $0{ }^{\circ} \mathrm{C}$. Then,
$\mathrm{POCl}_{3}(2.00 \mathrm{~mL}, 3.29 \mathrm{~g}, 21.50 \mathrm{mmol})$ was added dropwise with stirring in an ice bath (keeping the temperature at $0-5{ }^{\circ} \mathrm{C}$ ) to form a light red solution. After stirring the mixture for $2 \mathrm{~h}$, Compound $1(0.50 \mathrm{~g}, 1.90 \mathrm{mmol})$ was slowly added under the protection of argon and stirred for two hours. The mixture was moved to room temperature and stirred overnight. After the reaction was completed, the solution was stirred and poured into an appropriate amount of crushed ice. The solution was neutralized to $\mathrm{pH}=7-8$ with sodium carbonate, and a reddish brown solid was formed. The product was filtered, washed with ice-cold water, and dried to obtain $0.47 \mathrm{~g}$ of brick red powder with a yield of $80.00 \%$.

Synthesis of compound 3: Synthesized according to reference ( $\mathrm{Li}$ et al. 2014) and made minor improvements. In a $25-\mathrm{mL}$ round-bottom flask, dissolve o-aminothiophenol $(1.10 \mathrm{~mL}, 1.25 \mathrm{~g}, 10.00 \mathrm{mmol})$ and malononitrile $(0.66 \mathrm{~g}, 10.00 \mathrm{mmol})$ in $5 \mathrm{~mL}$ methanol. Dissolve $0.57 \mathrm{~mL}$ of glacial acetic acid in $10 \mathrm{~mL}$ of methanol and slowly add dropwise to the round-bottom flask. The mixed solution was stirred at room temperature for $2.5 \mathrm{~h}$, and a large amount of yellow precipitate was deposited, which was 
filtered and dried to obtain $0.8266 \mathrm{~g}$ of light yellow powder with a yield of $47.50 \%$.

Synthesis of probe BCD: Compound 2 (0.47 g, $15.40 \mathrm{mmol})$ and compound $3(0.30 \mathrm{~g}, 17.20 \mathrm{mmol})$ were dissolved in $20 \mathrm{~mL} \mathrm{CH}_{2} \mathrm{Cl}_{2}$ and heated to reflux for $12 \mathrm{~h}$. After the reaction was completed, it was cooled to room temperature, then vacuum-filtered, washed with $\mathrm{CH}_{2} \mathrm{Cl}_{2}$ three times, and dried to obtain $0.21 \mathrm{~g}$ of dark purple powder with a yield of $28.90 \%:{ }^{1} \mathrm{H}$ NMR (Additional file 1: Fig. S1) $\left(400 \mathrm{MHz}, \mathrm{CDCl}_{3}\right) \delta 1.25(\mathrm{~d}, \mathrm{~J}=7.1 \mathrm{~Hz}, 6 \mathrm{H})$, $3.47(\mathrm{t}, \mathrm{J}=7.1 \mathrm{~Hz}, 4 \mathrm{H}), 6.50(\mathrm{~d}, \mathrm{~J}=2.3 \mathrm{~Hz}, 1 \mathrm{H}), 6.63(\mathrm{dd}$, $\mathrm{J}=8.9,2.5 \mathrm{~Hz}, 1 \mathrm{H}), 7.35-7.53(\mathrm{~m}, 3 \mathrm{H}), 7.81-7.90(\mathrm{~m}, 1 \mathrm{H})$, $8.07(\mathrm{~d}, \mathrm{~J}=7.4 \mathrm{~Hz}, 1 \mathrm{H}), 8.27(\mathrm{~s}, 1 \mathrm{H}), 8.43(\mathrm{~d}, \mathrm{~J}=11.6 \mathrm{~Hz}$, $1 \mathrm{H}), 8.54(\mathrm{~d}, \mathrm{~J}=11.6 \mathrm{~Hz}, 1 \mathrm{H}) .{ }^{13} \mathrm{C}$ NMR (Additional file 1 : Fig. S2) $\left(101 \mathrm{MHz}, \mathrm{CDCl}_{3}\right) \delta 12.56,45.23,96.73,97.15$, $107.78,108.50,109.78,115.27,121.67,123.81,126.17$, $126.97,127.29,130.42,130.80,135.11,141.41,142.26$, 142.91, 145.86, 152.40, 153.99, 161.51. HRMS (Additional file 1: Fig. S3): calc. for $\mathrm{C}_{25} \mathrm{H}_{20} \mathrm{ClN}_{3} \mathrm{O}_{2} \mathrm{~S}: 461.9640$, found: 462.1034 .

\section{Results and discussion}

\section{Spectral response of probe $B C D$ to $\mathrm{N}_{2} \mathrm{H}_{4}$}

In order to evaluate the spectral response of $B C D$ to $\mathrm{N}_{2} \mathrm{H}_{4}$, an optical response experiment was performed on $\mathrm{N}_{2} \mathrm{H}_{4}$ in DMF/Hepes $(\mathrm{v} / \mathrm{v}=7: 3, \mathrm{pH}=7.4)$. From the ultraviolet-visible spectrum in Fig. 1, it can be seen that the probe $\mathrm{BCD}$ has the maximum absorption wavelength at $517 \mathrm{~nm}$. After adding hydrazine hydrate, the maximum absorption peak at $517 \mathrm{~nm}$ disappears, and a new one appears at $407 \mathrm{~nm}$. The strong absorption peak indicates that the addition of hydrazine hydrate reacts with the probe $\mathrm{BCD}$ to destroy the original conjugation structure of the probe molecule.

It can be seen from Fig. 2a that after adding hydrazine hydrate, the fluorescent intensity of BCD is significantly

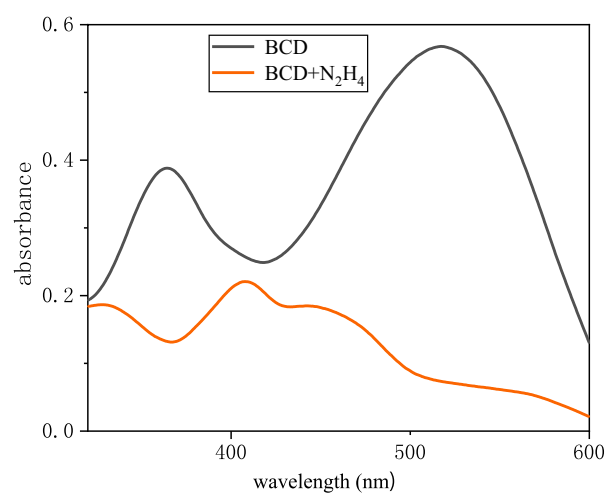

Fig. 1 UV-Vis absorbance spectra of probe $B C D(60 \mu \mathrm{M})$ in the absence and presence of $\mathrm{N}_{2} \mathrm{H}_{4}(10 \mathrm{mM})$ in the DMF-Hepes buffer $(7 / 3$, $\mathrm{v} / \mathrm{v}, \mathrm{pH}=7.4)$ enhanced, and the fluorescent intensity of the solution reaches an equilibrium state in about $2 \mathrm{~h}$. In order to explore the $\mathrm{pH}$ stability of $\mathrm{BCD}$ and its applicable $\mathrm{pH}$ range, the fluorescent intensity of $\mathrm{BCD}(60 \mu \mathrm{M})$ in the absence and presence of $\mathrm{N}_{2} \mathrm{H}_{4}(100 \mu \mathrm{M})$ was measured under different $\mathrm{pH}$ conditions. In the absence of $\mathrm{N}_{2} \mathrm{H}_{4}$, the fluorescent intensity of $\mathrm{BCD}$ varies slightly from $\mathrm{pH}$ 1.0 to 11.0 , indicating that the probe is stable over a wide $\mathrm{pH}$ range (Fig. $2 \mathrm{~b}$ ).

When $\mathrm{N}_{2} \mathrm{H}_{4}$ is not added, the maximum absorption peak of BCD is at $517 \mathrm{~nm}$. Within $3 \mathrm{~min}$, the absorbance of the solution at $517 \mathrm{~nm}$ gradually increases and a slight red shift $(3 \mathrm{~nm})$ occurs; from 3 to $38 \mathrm{~min}$, the absorbance at $517 \mathrm{~nm}$ gradually decreases, and a new strong absorption peak appears at $450 \mathrm{~nm}$; from 38 to $120 \mathrm{~min}$, the intensity of the strong absorption peak at $450 \mathrm{~nm}$ gradually decreases, and finally a strong absorption peak appears at $407 \mathrm{~nm}$. The time-varying UV-Vis spectra of the BCD solution after the addition of $\mathrm{N}_{2} \mathrm{H}_{4}$ also indirectly proves that hydrazine hydrate and $\mathrm{BCD}$ are not completely reacted in one step, but have substitution reactions with cyano groups and active chlorine atoms (Fig. 3).

The fluorescence spectrum of $B C D$ is shown in Fig. 4a. The probe $\mathrm{BCD}$ has almost no fluorescence in Hepes buffer. As the concentration of hydrazine increases, the fluorescent intensity of BCD at $458 \mathrm{~nm}(\lambda \mathrm{ex}=407 \mathrm{~nm})$ increases by about 637 times. The concentration of $\mathrm{N}_{2} \mathrm{H}_{4}$ and the fluorescent intensity of BCD at $458 \mathrm{~nm}$ showed a good linear relationship in the range of $100-1500 \mu \mathrm{M}$. The calculation found that the limit of detection (LOD) was $9.98125 \mu \mathrm{M}$ (based on $3 \mathrm{~s} / \mathrm{k}$, where $\mathrm{s}$ is the standard deviation of the blank measurement and $k$ is the slope of the linearity of the fluorescent intensity and the sample concentration curve).

\section{Spectral response of probe $B C D$ to biothiol}

Homocysteine(Hcy) is a heterogeneous amino acid cysteine (Cys), which contains an extra methylene group (-CH2-) before the thiol group $(-\mathrm{SH})$ in the side chain. In order to study the spectral response of $\mathrm{BCD}$ to biological thiols, the sensing characteristics of biological thiols were tested in DMF/Hepes $(\mathrm{v} / \mathrm{v}=8: 2$, $\mathrm{pH}=7.4$ ) aqueous solution. After Cys was added, the strong absorption peak of BCD at $516 \mathrm{~nm}$ was blueshifted, while the strong absorption peak at $365 \mathrm{~nm}$ was red-shifted (Fig. 5a). Compared with the addition of Cys, the strong absorption peak at $516 \mathrm{~nm}$ did not undergo a significant blue shift after adding Hcy to the BCD solution, but the strong absorption peak at $365 \mathrm{~nm}$ also exhibited a red shift (Fig. 5b). After the BCD solution was added to GSH, there was no obvious 
(a)

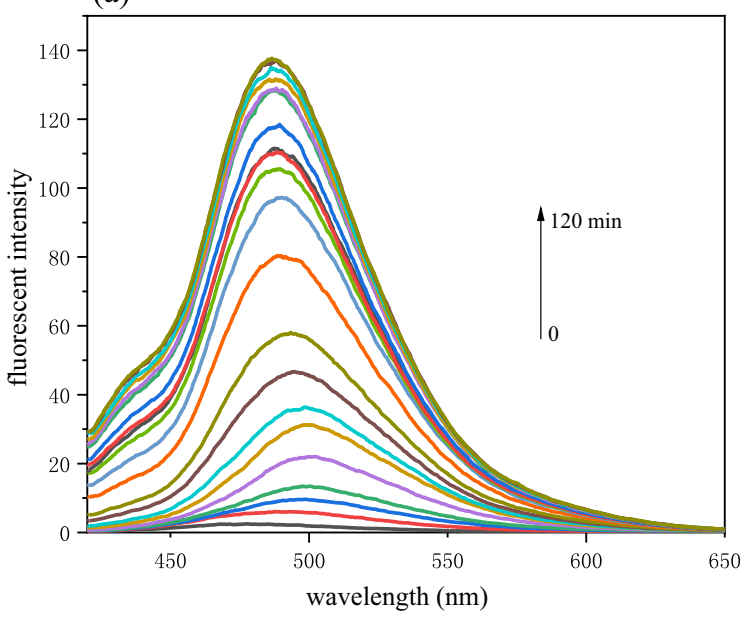

(b)

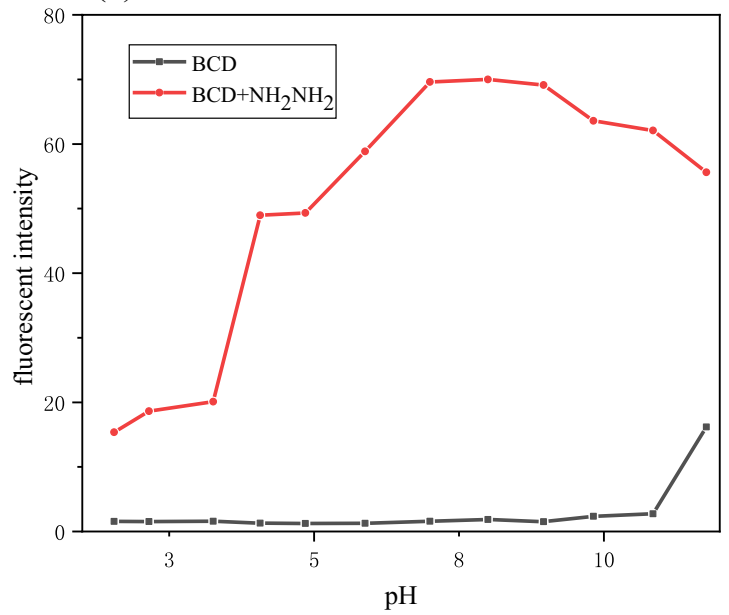

Fig. 2 a Time-dependent fluorescence spectral changes of probe BCD (60 $\mu M)$ after treatment with $\mathrm{N}_{2} \mathrm{H}_{4}(100 \mu \mathrm{M})$ in the DMF-Hepes buffer (7/3, $\mathrm{v} / \mathrm{v}, \mathrm{pH}=7.4), \lambda e x=407 \mathrm{~nm}$; b Fluorescent intensity at $458 \mathrm{~nm}$ of BCD (60 $\mu \mathrm{M})$ at various $\mathrm{pH}$ values in DMF-Hepes buffer $(7 / 3, \mathrm{v} / \mathrm{v}, \mathrm{pH}=7.4) \mathrm{medium}$ in the absence and presence of $\mathrm{N}_{2} \mathrm{H}_{4}(100 \mu \mathrm{M})$, $\lambda$ ex $=407 \mathrm{~nm}$

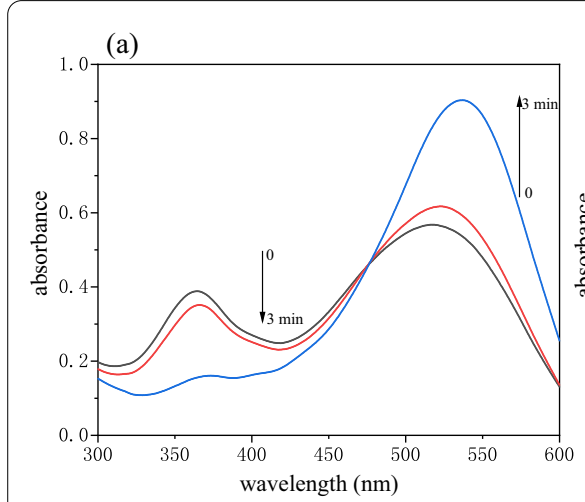

(b)

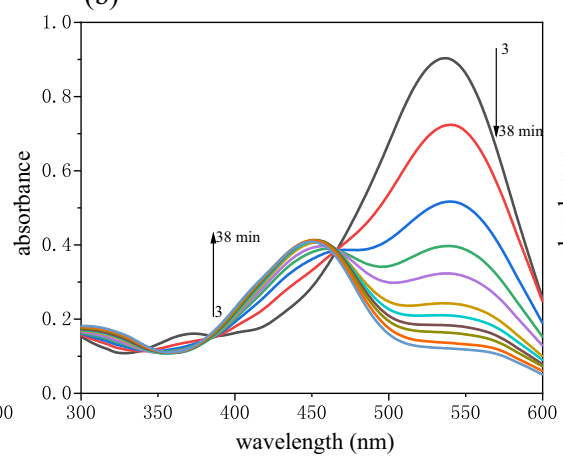

(c)

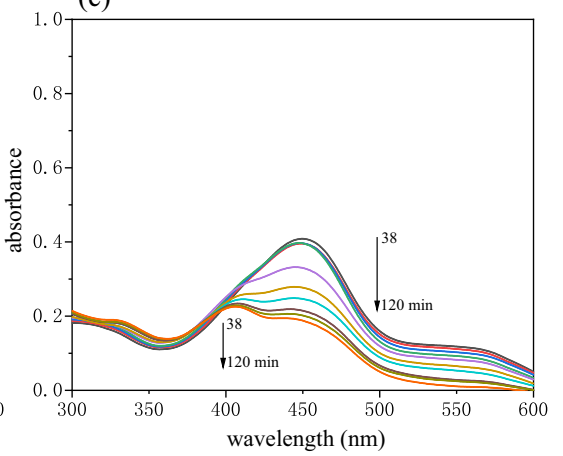

Fig. 3 Time-dependent absorption spectra of probe BCD (60 $\mu \mathrm{M})$ at different time scales upon addition of $\mathrm{N}_{2} \mathrm{H}_{4}(100 \mu \mathrm{M})$ in $\mathrm{DMF}-\mathrm{Hepes}$ buffer $(7 / 3$, $\mathrm{v} / \mathrm{v}, \mathrm{pH}=7.4)$

red-shift or blue-shift in the strong absorption peak at $516 \mathrm{~nm}$ or $365 \mathrm{~nm}$ (Fig. 5c). It can be seen from the UV-Vis spectra of the concentration of biological thiols that the conjugation of the final product of the reaction between BCD and different biological thiols is different.

Similarly, in order to explore the stability of the probe in the buffer solution (DMF/Hepes $=8: 2$ ), the fluorescent intensity of $\mathrm{BCD}$ under different $\mathrm{pH}$ environments was measured. It can be seen from Fig. 6 that the probe is hardly affected by the environmental $\mathrm{pH}$. After adding biothiol, the fluorescent intensity of the solution changed. In general, the monitoring effect of $\mathrm{BCD}$ on biological thiols is very good in a neutral environment.

When Cys is not added, BCD has two strong absorption peaks: $516 \mathrm{~nm}$ and $365 \mathrm{~nm}$. Within $10 \mathrm{~min}$, the absorbance of the solution at $516 \mathrm{~nm}$ gradually increased and a red shift $(20 \mathrm{~nm})$ occurred. From 10 to $40 \mathrm{~min}$, the absorbance at $516 \mathrm{~nm}$ does not change much, while the absorbance at $365 \mathrm{~nm}$ gradually increases; from 40 to $360 \mathrm{~min}$, the intensity of the strong absorption peak at $365 \mathrm{~nm}$ gradually increases and gradually red-shifts, forming a new strong absorption peak at $399 \mathrm{~nm}$, while the intensity of the strong absorption peak at $516 \mathrm{~nm}$ gradually weakens and appears at $497 \mathrm{~nm}$ isoabsorbent point; after $360-600 \mathrm{~min}$, the intensity of the strong absorption peak at $365 \mathrm{~nm}$ gradually increased, and the BCD solution finally formed new absorption peaks at $463 \mathrm{~nm}$ and $399 \mathrm{~nm}$. It can be seen from the time-ultraviolet diagram of the $\mathrm{BCD}$ solution after adding Cys that Cys and $\mathrm{BCD}$ have undergone a series of reactions, which 
Chen et al. J Anal Sci Technol

(2021) 12:50

Page 6 of 12

(a)

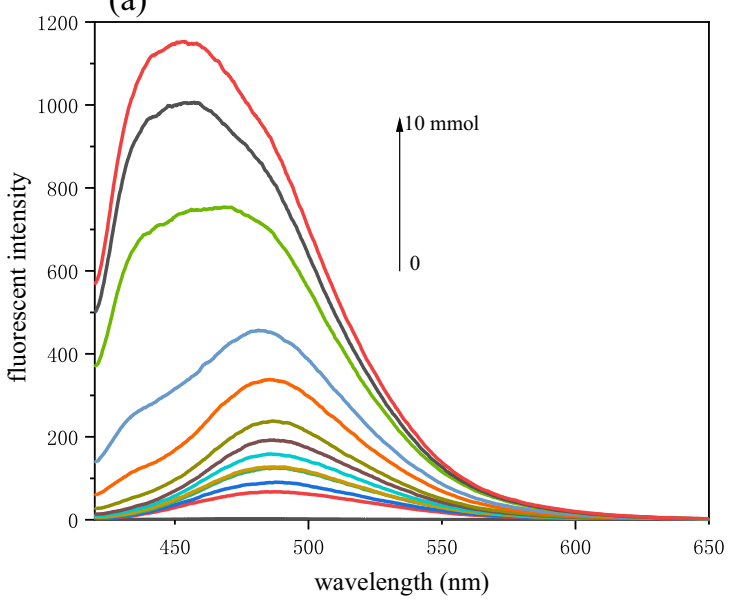

(b)

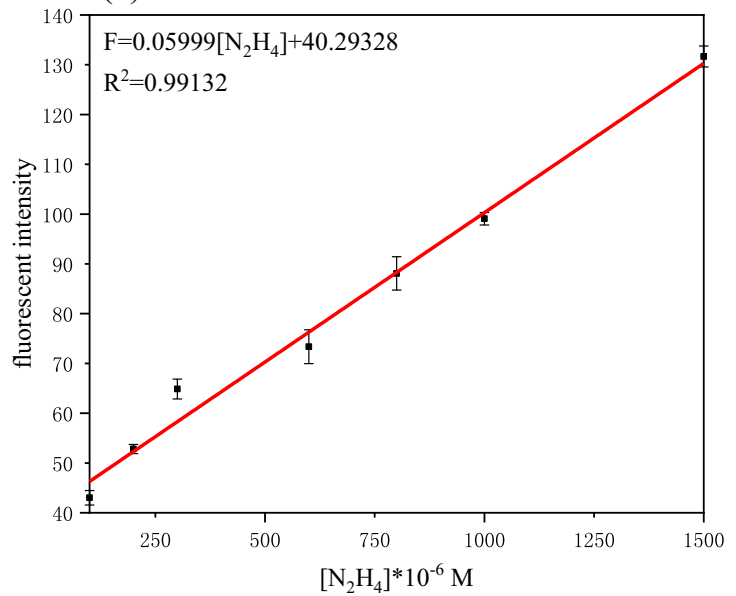

Fig. 4 a Fluorescence spectral changes of $B C D(60 \mu M)$ toward different concentrations of $\mathrm{N}_{2} \mathrm{H}_{4}$ in the DMF-Hepes buffer $(7 / 3, v / v, p H=7.4)$. $\mathbf{b}$ Linear responses of fluorescent intensity at $458 \mathrm{~nm}$ to varying $\mathrm{N}_{2} \mathrm{H}_{4}$ concentration

(a)

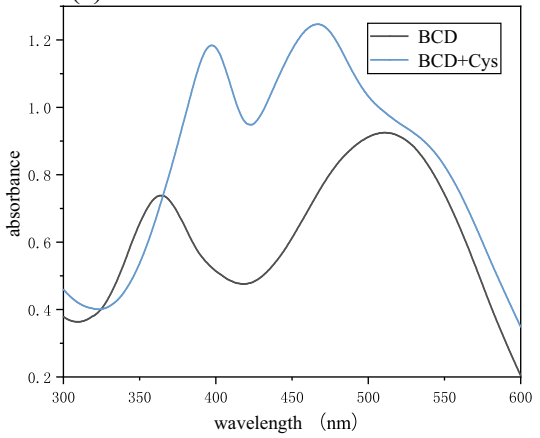

(b)

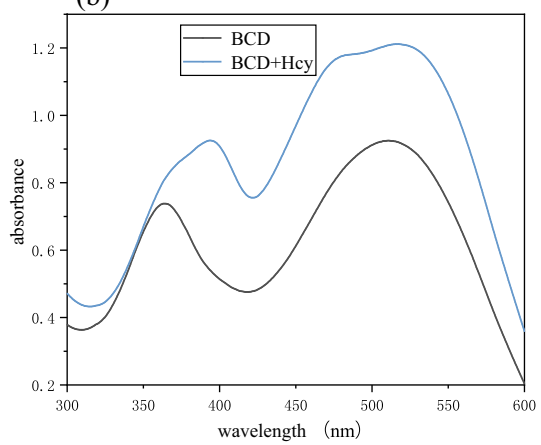

(c)

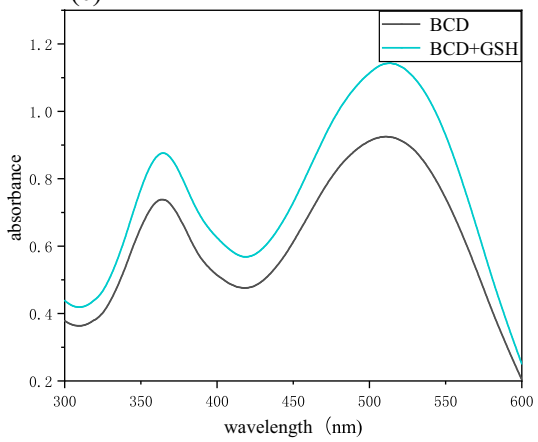

Fig. 5 a UV-Vis absorbance spectra of probe BCD $(60 \mu \mathrm{M})$ in the absence and presence of Chs $(1.4 \mathrm{mM})$ in the DMF-Hepes buffer $(8 / 2, v / V$, $\mathrm{pH}=7.4)$. $\mathbf{b} U \mathrm{~V}$-Vic absorbance spectra of probe BCD $(60 \mu \mathrm{M})$ in the absence and presence of Hoy $(1.4 \mathrm{mM})$ in the DMF-Hepes buffer $(8 / 2, \mathrm{v} / \mathrm{v}$, $\mathrm{pH}=7.4)$. $\mathbf{c} \cup V-V i s$ absorbance spectra of probe BCD $(60 \mu \mathrm{M})$ in the absence and presence of GSH $(1.4 \mathrm{mM})$ in the DMF-Hepes buffer $(8 / 2, \mathrm{~V} / \mathrm{V}$, $\mathrm{pH}=7.4)$

(a)

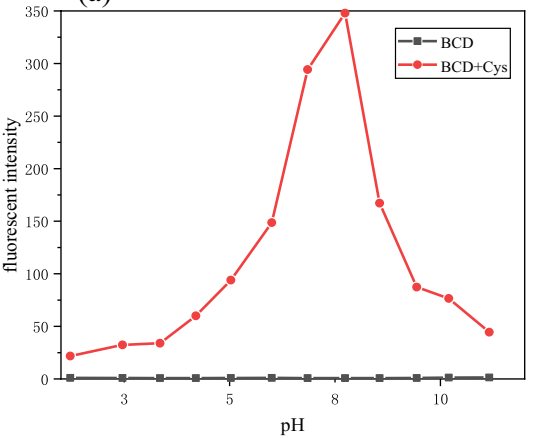

(b)

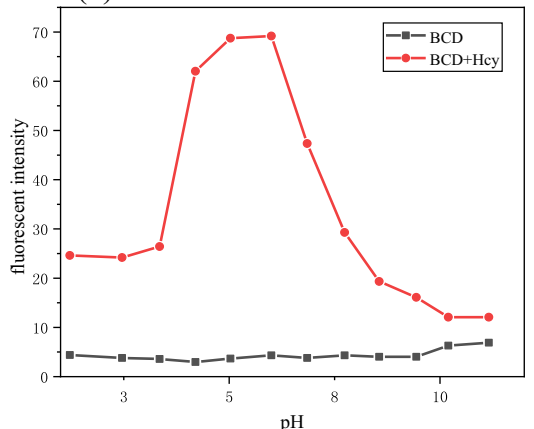

(c)

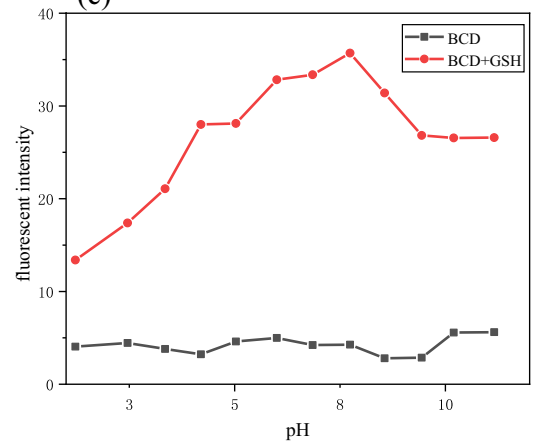

Fig. 6 a Fluorescent intensity at $502 \mathrm{~nm}$ of $\mathrm{BCD}(60 \mu \mathrm{M})$ at various $\mathrm{pH}$ values in DMF-Hepes buffer $(8 / 2, \mathrm{v} / \mathrm{v}, \mathrm{pH}=7.4)$ medium in the absence and presence of Chs $(1 \mathrm{mM}), \lambda e x=463 \mathrm{~nm}$. b Fluorescent intensity at $479 \mathrm{~nm}$ of BCD $(60 \mu \mathrm{M})$ at various $\mathrm{pH}$ values in DMF-Hepes buffer $(8 / 2, \mathrm{v} / \mathrm{v}$, $\mathrm{pH}=7.4)$ medium in the absence and presence of Hey $(1 \mathrm{mM}), \lambda e x=396 \mathrm{~nm}$. $\mathbf{c}$ Fluorescent intensity at $476 \mathrm{~nm}$ of BCD $(60 \mu \mathrm{M})$ at various $\mathrm{pH}$ values in DMF-Hepes buffer (8/2, vav, pH =7.4) medium in the absence and presence of $\mathrm{GSH}(1 \mathrm{mM}), \lambda e x=365 \mathrm{~nm}$ 
can also support the speculation of the detection mechanism of $\mathrm{BCD}$ for biothiols later.

Within $15 \mathrm{~min}$, the absorbance of the solution at $516 \mathrm{~nm}$ gradually increased and a slight red shift occurred; from 15 to $65 \mathrm{~min}$, the strong absorption peak at $516 \mathrm{~nm}$ gradually weakened, while the absorbance at $365 \mathrm{~nm}$ increased; from 65 to $150 \mathrm{~min}$, the intensity of the strong absorption peak at $365 \mathrm{~nm}$ gradually weakened and gradually red-shifted, while the intensity of the strong absorption peak at $516 \mathrm{~nm}$ gradually increased; from 150 to $540 \mathrm{~min}$, the intensity of the strong absorption peak at $365 \mathrm{~nm}$ gradually increased and red-shifted to $396 \mathrm{~nm}$, the absorbance at $516 \mathrm{~nm}$ gradually decreased, and an isosbestic point appeared at $490 \mathrm{~nm}$. The comparison between Fig. 7 and Fig. 8 can prove indirectly that the reaction of Cys and $\mathrm{BCD}$ to form

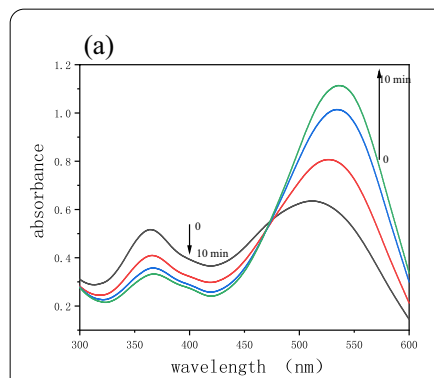

\section{(b)}

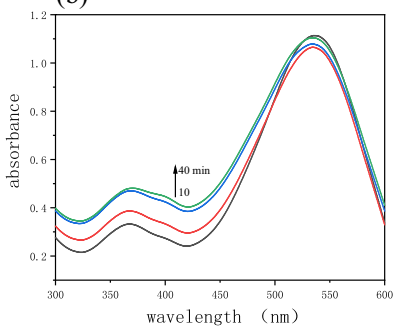

(c)

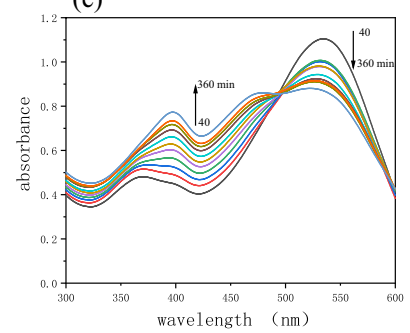

(d)

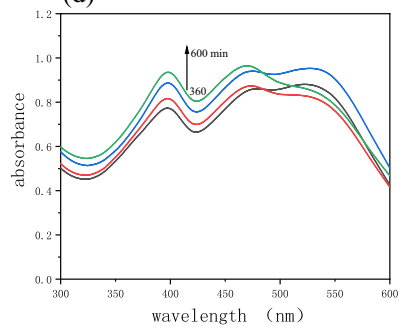

Fig. 7 Time-dependent absorption spectra of probe BCD $(60 \mu \mathrm{M})$ at different time scales upon addition of Cys (1 mM) in DMF-Hepes buffer (8/2, $\mathrm{v} / \mathrm{V}, \mathrm{pH}=7.4)$

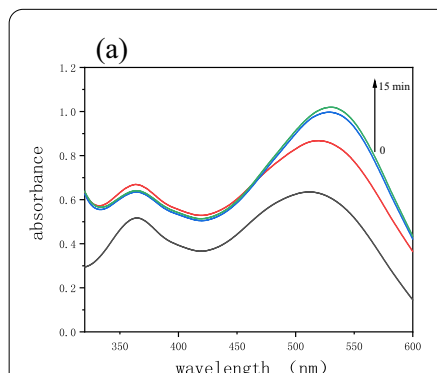

(b)

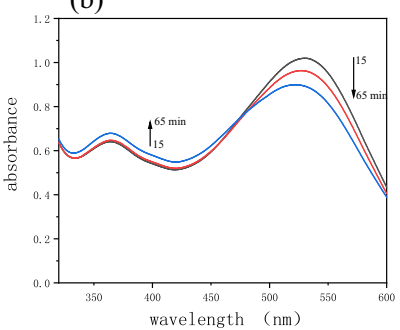

(c)

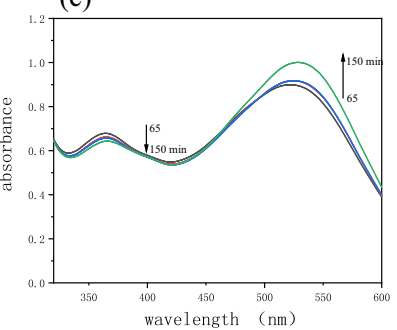

(d)

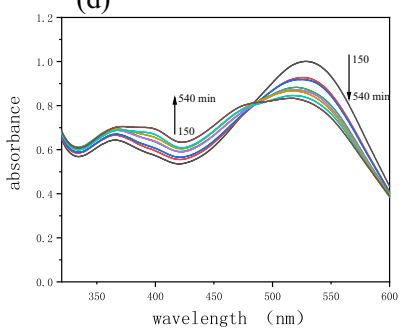

Fig. 8 Time-dependent absorption spectra of probe BCD $(60 \mu \mathrm{M})$ at different time scales upon addition of Hcy (1 mM) in DMF-Hepes buffer ( $8 / 2$, $\mathrm{v} / \mathrm{v}, \mathrm{pH}=7.4)$
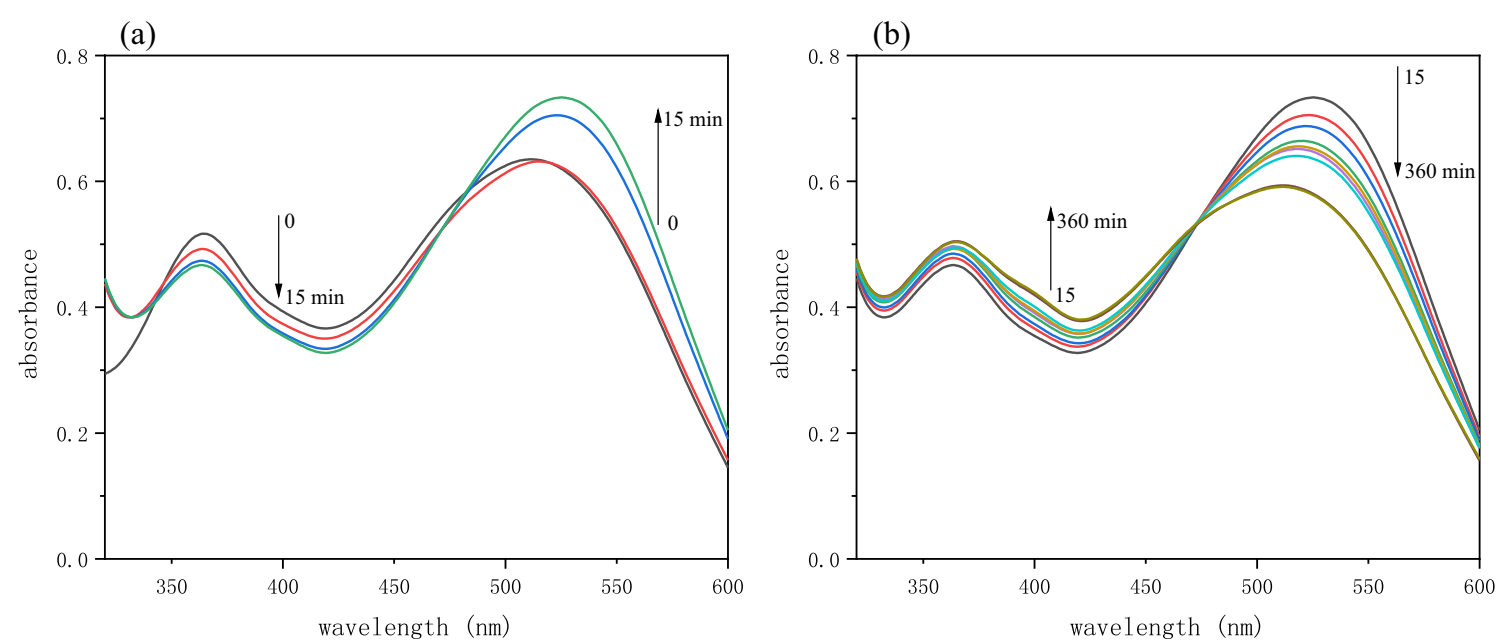

Fig. 9 Time-dependent absorption spectra of probe BCD $(60 \mu \mathrm{M})$ at different time scales upon addition of GSH (1 mM) in DMF-Hepes buffer (8/2, $\mathrm{v} / \mathrm{v}, \mathrm{pH}=7.4$ ) 
(a)

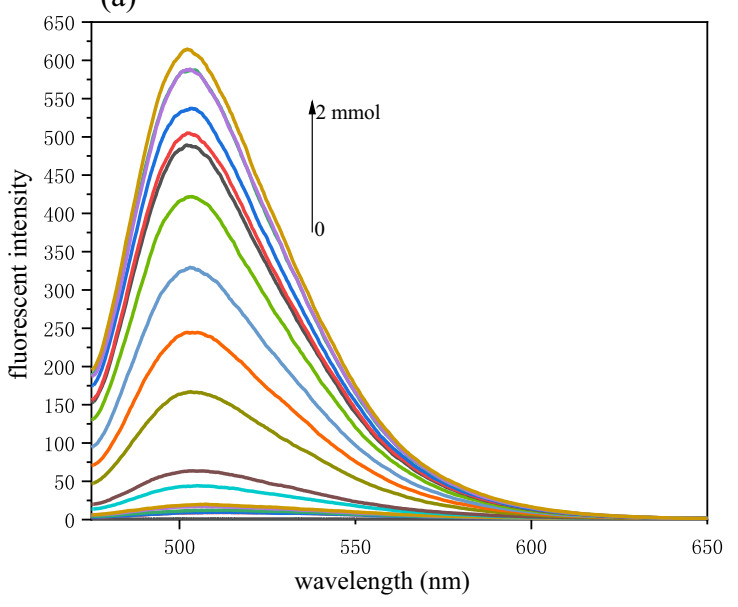

(c)

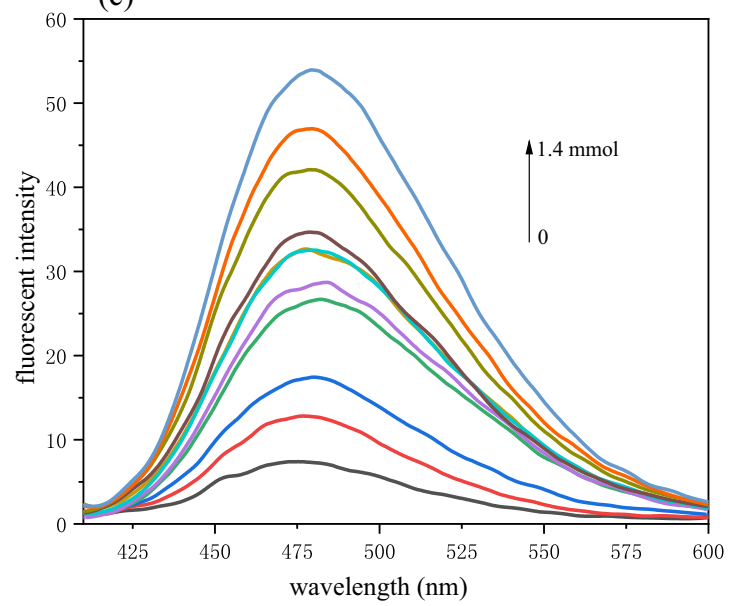

(e)

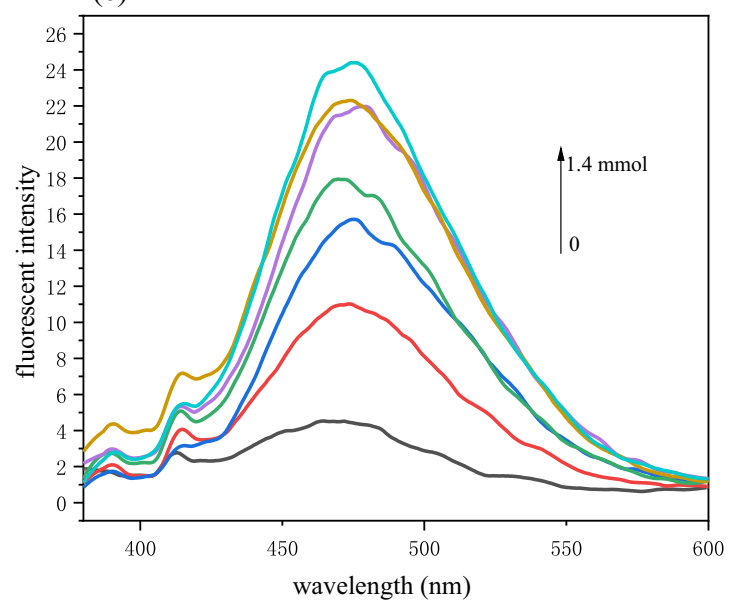

(b)

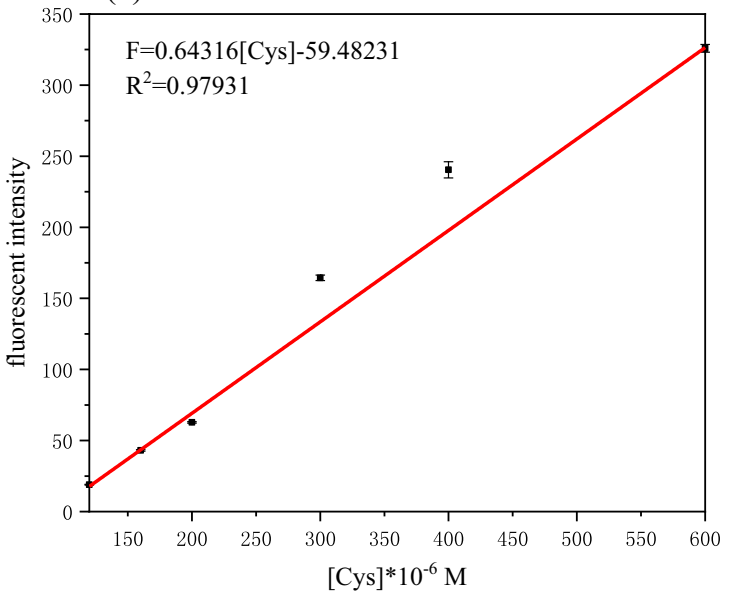

(d)

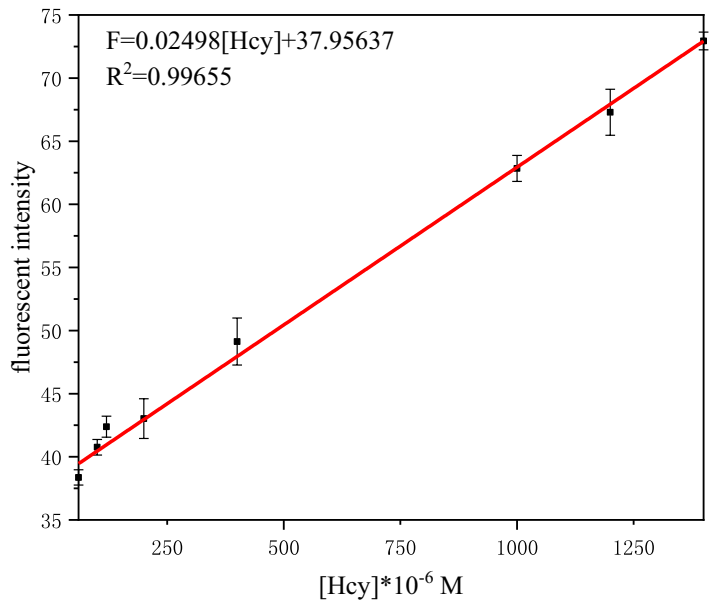

(f)

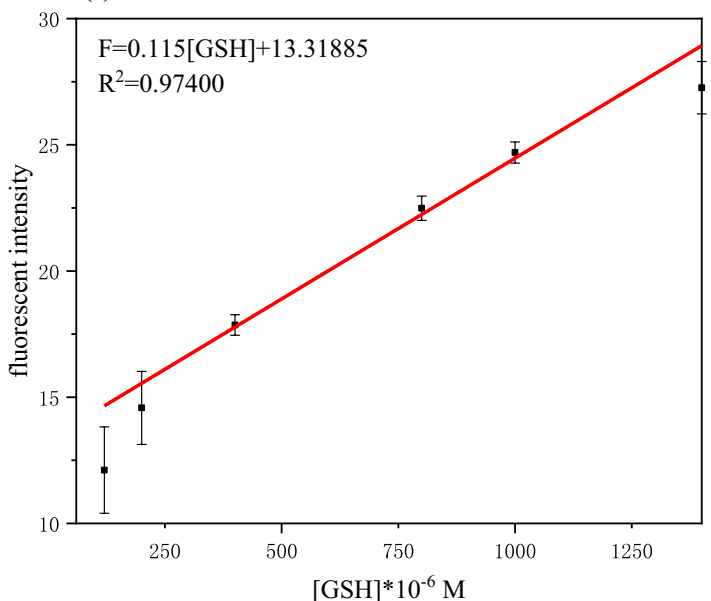

Fig. 10 a Fluorescence spectral changes of $B C D(60 \mu \mathrm{M})$ toward different concentrations of Cys in the DMF-Hepes buffer $(8 / 2, v / v, p H=7.4)$. b Linear responses of fluorescent intensity at $502 \mathrm{~nm}$ to varying Hcy concentration. c Fluorescence spectral changes of BCD $(60 \mu \mathrm{M})$ toward different concentrations of Hcy in the DMF-Hepes buffer $(8 / 2, \mathrm{v} / \mathrm{v}, \mathrm{pH}=7.4)$. $\mathbf{d}$ Linear responses of fluorescent intensity at $479 \mathrm{~nm}$ to varying Cys concentration. e Fluorescence spectral changes of BCD $(60 \mu \mathrm{M})$ toward different concentrations of GSH in the DMF-Hepes buffer $(8 / 2, \mathrm{v} / \mathrm{v}, \mathrm{pH}=7.4)$. f $L$ inear responses of fluorescent intensity at $476 \mathrm{~nm}$ to varying GSH concentration 
a cyclic compound is much easier than the reaction of Hcy and BCD to form a cyclic compound.

Within $15 \mathrm{~min}$, the absorbance of the solution at $516 \mathrm{~nm}$ gradually increased, and a slight red shift $(12 \mathrm{~nm})$ occurred; from 15 to $360 \mathrm{~min}$, the strong absorption peak at $516 \mathrm{~nm}$ gradually weakened, while the absorbance at $365 \mathrm{~nm}$ increased. Comparing Fig. 9 with Figs. 7 and 8, we can find that GSH and BCD hardly generate cyclic compounds.

It can be found from Fig. 10 that after adding biothiol, the fluorescent intensity of the $\mathrm{BCD}$ solution has increased to varying degrees. As the concentration of Cys increases, the fluorescent intensity of the solution at $502 \mathrm{~nm}(\lambda \mathrm{ex}=463 \mathrm{~nm})$ increases significantly, approximately 760 times (Fig. 10a). After adding Hcy, the fluorescent intensity of the BCD solution at $479 \mathrm{~nm}(\lambda \mathrm{ex}=396 \mathrm{~nm})$ increased approximately 8 times (Fig. 10c). After adding GSH to the BCD solution, the fluorescent intensity at $476 \mathrm{~nm}(\lambda \mathrm{ex}=365 \mathrm{~nm})$ was slightly increased (Fig. 10e). Calculations found that the limits of detection (LOD) for Cys, Hcy, and GSH were $0.9825 \mu \mathrm{M}$, $135.6225 \mu \mathrm{M}$, and $243.9945 \mu \mathrm{M}$, respectively.

\section{Study on the selectivity of $B C D$}

In order to evaluate the selectivity of $B C D$ to $\mathrm{N}_{2} \mathrm{H}_{4}$ and biothiols and other small biomolecules, various related species were studied, including common amino acids (Thr, Ile, His, Glu, Ala, Gly, Ser, Met, Phe, Pro, Leu, Asn, Lys, Val) anions $\left(\mathrm{HSO}_{3}{ }^{-}, \mathrm{SO}_{4}{ }^{2-}, \mathrm{ClO}^{-}, \mathrm{I}^{-}, \mathrm{NO}_{3}{ }^{-}\right)$, metal ions $\left(\mathrm{Na}^{+}, \mathrm{Mg}^{2+}, \mathrm{Ca}^{2+}, \mathrm{Ag}^{+}, \mathrm{Al}^{3+}, \mathrm{K}^{+}, \mathrm{Mn}^{2+}, \mathrm{Zn}^{2+}, \mathrm{Ni}^{2+}\right.$,
$\left.\mathrm{Cd}^{2+}, \mathrm{Ba}^{2+}, \mathrm{Co}^{2+}\right)$, triethylamine and piperidine. As shown in Fig. 11a, after adding $\mathrm{N}_{2} \mathrm{H}_{4}$, the fluorescence of the $\mathrm{BCD}$ solution was greatly enhanced, and the fluorescence color was blue. Unlike $\mathrm{N}_{2} \mathrm{H}_{4}, \mathrm{BCD}$ emits green fluorescence with the addition of Cys. In contrast, the changes in fluorescent intensity caused by other small molecules are negligible, and no obvious changes in fluorescence color are observed. These results indicate that BCD is more selective for $\mathrm{N}_{2} \mathrm{H}_{4}$ and biothiols than other species. Therefore, $B C D$ has specific detection for $\mathrm{N}_{2} \mathrm{H}_{4}$ and biothiols in aqueous solution.

\section{Research on sensing mechanism}

By analyzing the reaction time diagrams of BCD with biological mercaptans and hydrazine hydrate (as shown in Figs. 3, 7, 8 and 9), the reaction mechanism is inferred as shown in Scheme 2. The probe BCD is composed of coumarin dye and benzothiazole acetonitrile and has four potential reaction sites. The chlorine atom (site 1) in the probe can be used as a leaving group to undergo SNAr nucleophilic substitution with a sulfhydryl group; $\alpha, \beta$-unsaturated bond (site 2) can be used as acceptor for Michael addition reaction; Cyano group (site 3) can be used as electrophile; under the action of the cyano group, the unsaturated bond in the benzothiazole moiety (position 4) can be used as another reaction site to distinguish biological thiols. The reaction site of the probe BCD is the same as that in reference (Yin et al. 2018), so it is speculated that the reaction mechanism of $B C D$ and biothiol is consistent with the reference. Utilizing the (a)

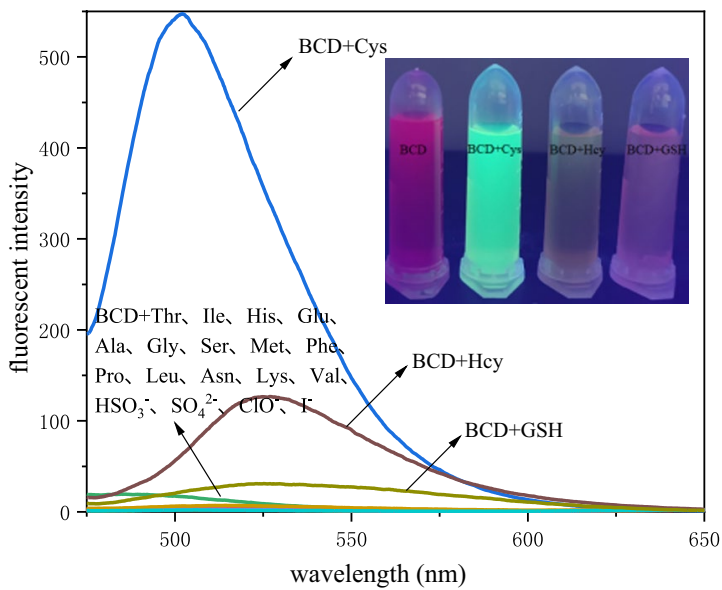

(b)

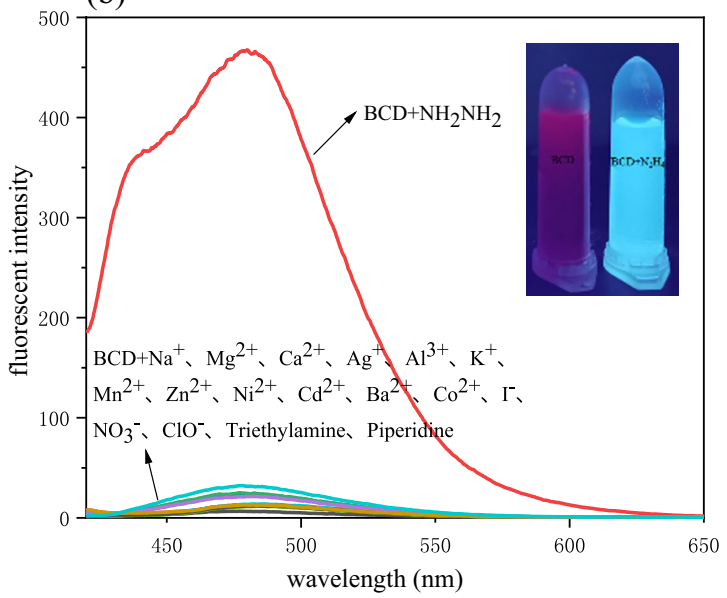

Fig. 11 a Fluorescence spectra of probe $B C D(60 \mu \mathrm{M})$ in the presence of other species $(1 \mathrm{mM})$ in the DMF-Hepes buffer $(8 / 2, \mathrm{v} / \mathrm{v}, \mathrm{pH}=7.4)$, $\lambda \mathrm{ex}=463 \mathrm{~nm}$. Inset: color of the solution containing BCD $(60 \mu \mathrm{M})$ before and after the addition of Cys (1.4 mM), Hcy (1.4 mM), GSH (1.4 mM) in the DMF-Hepes buffer (8/2, v/v, pH =7.4) under $365 \mathrm{~nm}$ UV light. b Fluorescence spectra of probe BCD (60 $\mu M)$ in the presence of other species $(400 \mu \mathrm{M})$ in the DMF-Hepes buffer $(7 / 3, \mathrm{v} / \mathrm{v}, \mathrm{pH}=7.4)$, $\lambda$ ex $=407 \mathrm{~nm}$. Inset: color of the solution containing $\mathrm{BCD}(60 \mu \mathrm{M})$ before and after the addition of $\mathrm{N}_{2} \mathrm{H}_{4}(10 \mathrm{mM})$ in the DMF-Hepes buffer $(7 / 3, \mathrm{v} / \mathrm{V}, \mathrm{pH}=7.4)$ under $365 \mathrm{~nm}$ UV light 
<smiles>CCN(CC)c1ccc2cc(/C(Cl)=C/C=C(\C#N)c3nc4ccccc4s3)c(=O)oc2c1</smiles><smiles>CCN(CC)c1ccc2cc(/C(=C\C=C(/C#N)C(CS)NC(CS)C(=O)O)c3nc4ccccc4s3)c(=O)oc2c1</smiles>

2)<smiles>CCN(CC)c1ccc2cc(/C(=C/C=C(\C#N)c3nc4ccccc4s3)SCCC(N)C(=O)O)c(=O)oc2c1</smiles><smiles>CCN(CC)c1ccc2cc(/C(Cl)=C/C=C(\C#N)c3nc4ccccc4s3)c(=O)oc2c1</smiles><smiles></smiles>

3)<smiles>CCN(CC)c1ccc2cc(/C(Cl)=C/C=C(\C#N)c3nc4ccccc4s3)c(=O)oc2c1</smiles>

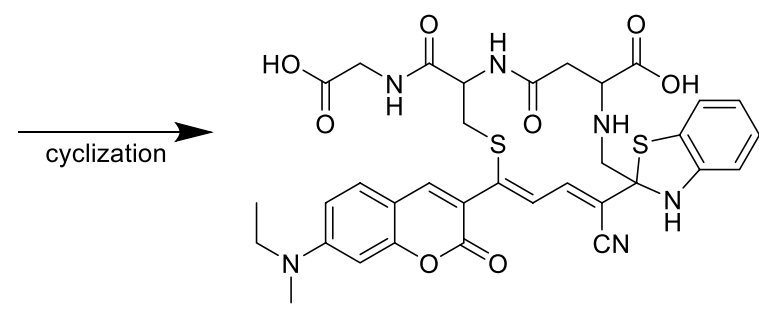<smiles>CCN(CC)c1ccc2cc(/C(Cl)=C/C=C(\C#N)c3nc4ccccc4s3)c(=O)oc2c1</smiles>

Scheme 2 Possible sensing mechanism of probe BCD: (1) proposed mechanisms of probe BCD with Cys; (2) proposed mechanisms of probe BCD with $\mathrm{Hcy}$; (3) proposed mechanisms of probe BCD with GSH; (4) proposed mechanisms of probe BCD with $\mathrm{N}_{2} \mathrm{H}_{4}$ 
nucleophilicity of biological thiol sulfhydryl groups, the chlorine atom is first substituted (site 1) and then intramolecular rearrangement occurs, achieving an intramolecular cyclization reaction (attack site 2 or 3). Due to the different chain lengths of Cys, Hcy, and GSH, it is easiest to attack site 2 to generate a seven-membered ring intermediate product when the probe reacts with Cys to undergo intramolecular cyclization (see Additional file 1: Fig. S5); when intramolecular cyclization occurs with Hcy, the offensive site 3 will generate a ten-membered ring intermediate product. From a kinetic point of view, it is far more difficult to form a seven-membered ring compound; when it reacts with GSH to undergo intramolecular cyclization, it will attack position 4 , which will generate a fourteen-membered ring compound, which is extremely difficult in terms of kinetics. Due to the difference in their spatial structure, they will combine with different reaction sites to generate different products, which will cause the color and fluorescence signal of the system to change, so as to achieve the purpose of detecting and distinguishing these three biological thiols. The strong electron-withdrawing group cyano group is used as the recognition site of hydrazine, and it reacts with hydrazine hydrate to form a hydrazone, which changes the pushpull structure and blue shifts in ultraviolet light. The active chlorine atom and hydrazine hydrate also undergo substitution reactions. The reaction mechanism is supported by HRMS (see Additional file 1: Fig. S6) and ${ }^{1} \mathrm{H}$ NMR spectra (see Additional file 1: Fig. S7).

\section{Conclusion}

In conclusion, in this work, a new type of open fluorescent probe $\mathrm{BCD}$ was designed and synthesized, which can simultaneously detect biological thiols and hydrazine. The structure of the probe BCD was confirmed by nuclear magnetic (NMR) and high-resolution mass spectrometry (HRMS). According to the literature, the reaction mechanism of $\mathrm{BCD}$ and biological mercaptan or hydrazine hydrate was speculated, and the reaction mechanism of BCD and hydrazine hydrate was supported by mass spectrometry data. Further research results on $\mathrm{BCD}$ show that the probe has excellent performance such as high sensitivity and strong specificity, and the probe $B C D$ has strong stability in weak acid and weak base environments, which is conducive to the detection of biological thiols or hydrazine hydrate.

\footnotetext{
Abbreviations

BCD: (2E,4Z)-2-(benzo[d]thiazol-2-yl)-5-chloro-5-(7-(diethylamino)-2oxo-2H-chromen-3-yl)penta-2,4-dienenitrile; Cys: Cysteine; Hcy: Homocysteine; GSH: Glutathione; $\mathrm{H}_{2}$ S: Hydrogen sulfide; AIDS: Acquired immunodeficiency syndrome; $\mathrm{N}_{2} \mathrm{H}_{4}$ : Hydrazine; US: United States; Cou-SBD-Cl: 3-(4-((7-Chlorobenzo[c] [1,2,5]oxadiazol-4-yl)sulfonyl) piperazine-1-carbonyl)-7-(diethylamino)-2H-chromen-2-one; Cou-Br:
}

10-(2-Bromoacetyl)-2,3,6,7-tetrahydro-1H,5H,11H-pyrano[2,3-f]pyrido[3,2,1-ij] quinolin-11-one; $\mathrm{HSO}_{3}{ }^{-}$: Bisulfite ion; $\mathrm{S}^{2-}$ : Sulfide; CMCA: Ethyl 2-cyano-3-(7(diethylamino)-2-oxo-2H-chromen-3-yl)propanoate; DMF: N,N-Dimethylformamide; Thr: Threonine; Ile: Isoleucine; His: Histidine; Glu: Glutamine acid; Ala: Alanine; Gly: Glycine; Ser: Serine; Met: Methionine; Phe: Phenylalanine; Pro: Proline; Leu: Leucine; Asn: Aspartic acid; Lys: Lysine; Val: Valine; $\mathrm{SO}_{4}{ }^{2-}$ : Sulfate ion; $\mathrm{ClO}^{-}$: Hypochlorite ion; $\mathrm{I}^{-}$: lodide; $\mathrm{NO}_{3}^{-}$: Nitrate ion; $\mathrm{Na}^{+}$: Sodium ion; $\mathrm{Mg}^{2+}$ : Magnesium; $\mathrm{Ca}^{2+}$ : Calcium ion; $\mathrm{Ag}^{+}$: Silver ion; $\mathrm{Al}^{3+}$ : Aluminum ion; $\mathrm{K}^{+}$: Potassium; $\mathrm{Mn}^{2+}$ : Manganese ion; $\mathrm{Zn}^{2+}$ : Zinc ions; $\mathrm{Ni}^{2+}$ : Nickel ion; $\mathrm{Cd}^{2+}$ : Cadmium ion; $\mathrm{Ba}^{2+}$ : Barium ion; $\mathrm{CO}^{2+}$ : Cobalt ion; $\mathrm{HAc}$ : Acetic acid; $\mathrm{MeOH}$ : Methanol; UV-Vis: Ultraviolet absorption spectrum; ${ }^{1} \mathrm{H}$ NMR: Hydrogen nuclear magnetic resonance; ${ }^{13} \mathrm{C}$ NMR: Carbon nuclear magnetic resonance; TMS: Tetramethylsilane; $\mathrm{POCl}_{3}$ : Phosphorus oxychloride; $\mathrm{CH}_{2} \mathrm{Cl}_{2}$ : Dichloromethane; HRMS: High-resolution mass spectrometry; Hepes: 2-[4-(2-Hydroxyethyl)1-piperazinyl]ethanesulfonicacid; LOD: Detection limit; NMR: Nuclear magnetic resonance.

\section{Supplementary Information}

The online version contains supplementary material available at https://doi. org/10.1186/s40543-021-00302-5.

Additional file 1: Fig. S1. HRMS spectrum of probe compound 2. Fig. S2. HRMS spectrum of probe BCD. Fig. S3. ${ }^{1} H$ NMR spectrum of probe BCD in $\mathrm{CDCl}_{3}$. Fig. S4. ${ }^{13} \mathrm{C}$ NMR spectrum of probe $\mathrm{BCD}$ in $\mathrm{CDCl}_{3}$. Fig. S5. The ${ }^{1} \mathrm{H}$ NMR spectra of $B C D$ were obtained in $C D C C_{3}$ and $B C D$-Cys were obtained in DMSO- $d_{6}$. Inset: the structures of probe BCD, probe BCD-Cys. Fig. $\mathbf{S 6}$. HRMS spectrum of probe BCD-NH $\mathrm{NH}_{2}$. Fig. S7. The ${ }^{1} \mathrm{H}$ NMR spectra of $\mathrm{BCD}$ were obtained in $\mathrm{CDCl}_{3}$ and $\mathrm{BCD}-\mathrm{NH}_{2} \mathrm{NH}_{2}$ were obtained in DMSO- $d_{6}$. Inset: the structures of probe $\mathrm{BCD}$, probe $\mathrm{BCD}-\mathrm{NH}_{2} \mathrm{NH}_{2}$.

\section{Acknowledgements}

This study was supported by the Hunan Provincial Natural Science Foundation of China (2019JJ40295) and Changsha University of Science and Technology Postgraduate Research and Innovation Project (CX2021SS81).

\section{Authors' contributions}

KC was mainly responsible for probe BCD synthesis, characterization and article writing; YL and JS were mainly responsible for data collection; HL was the corresponding author. All authors read and approved the final manuscript.

\section{Funding}

This study was supported by the Hunan Provincial Natural Science Foundation of China (2019JJ40295) and Changsha University of Science and Technology

Postgraduate Research and Innovation Project (CX2021SS81).

\section{Availability of data and materials}

All experiments were conducted in the School of Chemistry and Food Engineering, Changsha University of Science and Technology, Hunan, China. All data can be obtained from the corresponding author (Professor Li Heping) of the manuscript. Research data have been provided in the manuscript and supporting information files.

\section{Declarations}

\section{Competing interests}

The authors declare that they have no competing interests.

Received: 30 July 2021 Accepted: 14 October 2021

Published online: 28 October 2021

\section{References}

Baillet A, Chanteperdrix V, Trocmé C, et al. The role of oxidative stress in amyotrophic lateral sclerosis and Parkinson's disease. Neurochem Res. 2010;35:1530-7. https://doi.org/10.1007/s11064-010-0212-5. 
Balsamo A, Macchia B, Macchia F, Rossello A, Giani R, Pifferi G, Pinza M, Broccali G. Synthesis and antibacterial activities of new (a-Hydrazinobenzy 1 ) cephalosporin. J Med Chem. 1983;26:1648-50. https://doi.org/10.1021/ jm00365a019.

Borges-Santos MD, Moreto F, Pereira PC, et al. Plasma glutathione of $\mathrm{HIV}^{+}$ patients responded positively and differently to dietary supplementation with cysteine or glutamine. Nutrition. 2012;28:753-6. https://doi.org/10. 1016/j.nut.2011.10.014.

Chen F, Han D, Liu H, Wang S, Li KB, Zhang S, Shi W. A tri-site fluorescent probe for simultaneous sensing of hydrogen sulfide and glutathione and its bioimaging applications. Analyst. 2018;143:440-8. https://doi.org/10. 1039/C7AN01588G.

Cruz Vieira I, Omuro Lupetti K, Fatibello-Filho O. Sweet potato (ipomoea batatas (I.) lam.) tissue as a biocatalyst in a paraffin/graphite biosensor for hydrazine determination in boiler feed water. Anal Lett. 2002;35:2221-31. https://doi.org/10.1081/AL-120016097.

Debnath T, Dana J, Maity P, Lobo H, Shankarling GS, Ghosh HN. Restriction of molecular twisting on a gold nanoparticle surface. Chem A Eur J. 2015;21:5704-8. https://doi.org/10.1002/chem.201500044.

El-Kazak AM, El-Gohary NM, Badran AS, Ibrahim MA. Synthesis and chemical reactivity of the novel 3-chloro-3-(4-chlorocoumarin-3-yl)prop-2-enal. Tetrahedron. 2019;75(29):3923-32. https://doi.org/10.1016/j.tet.2019.06. 013.

Franco R, Schoneveld OJ, Pappa A, Panayiotidis MI. The central role of glutathione in the pathophysiology of human diseases. Arch Physiol Biochem. 2007;113:234-58. https://doi.org/10.1080/13813450701661198.

Garrod S, Bollard ME, Nicholls AW, et al. Integrated metabonomic analysis of the multiorgan effects of hydrazine toxicity in the rat. Chem Res Toxicol. 2005;18:115-22. https://doi.org/10.1021/tx0498915.

He L, Yang X, Xu K, Lin W. Improved aromatic substitution-rearrangementbased ratiometric fluorescent cysteine-specific probe and its application of real-time imaging under oxidative stress in living zebrafish. Anal Chem. 2017;89(17):9567-73. https://doi.org/10.1021/acs.analchem.7b02649.

Huffman CW, Godar EM, Ohki K, et al. Synthesis of hydrazine derivatives as plant growth inhibitors. J Agric Food Chem. 1968;16:1041-6. https://doi. org/10.1021/jf60160a035.

Jung HS, Chen X, Kim JS, Yoon J. Recent progress in luminescent and colorimetric chemosensors for detection of thiols. Chem Soc Rev. 2013;42:6019-31. https://doi.org/10.1039/C3CS60024F.

Li C, Wang S, Huang Y, Wen Q, Wang L, Kan Y. Photoluminescence properties of a novelcyclometalated iridium(III) complex withcoumarin-boronate and its recognition of hydrogen peroxide. Dalton Trans. 2014;43:5595-602. https://doi.org/10.1039/C3DT53498G.

Lu SC. Regulation of glutathione synthesis. Mol Asp Med. 2009;30:42-59. https://doi.org/10.1016/j.mam.2008.05.005.

Mo JW, Ogorevc B, Zhang X, Pihlar B. Cobalt and copper hexacyanoferrate modified carbon fiber microelectrode as an all-solid potentiometric microsensorfor hydrazine. Electroanal Int J Devoted Fundam Pract Aspects Electroanal. 2000;12(1):48-54. https://doi.org/10.1002/(SICI)15214109(20000101)12:1\%3c48::AID-ELAN48\%3e3.0.CO;2-H.

Puertas MC, Martínez-Martos JM, Cobo MP, et al. Plasma oxidative stress parameters in men and women with early stage Alzheimer type dementia. Exp Gerontol. 2012;8(47):625-30. https://doi.org/10.1016/j. exger.2012.05.019.

Sachdev P. Homocysteine, cerebrovascular disease and brain atrophy. J Neurol Sci. 2004;226:25-9. https://doi.org/10.1016/j.jns.2004.09.006.

Serov A, Kwak C. Direct hydrazine fuel cells: a review. Appl Catal B Environ. 2010;98:1-9. https://doi.org/10.1016/j.apcatb.2010.05.005.

Seshadri S, Beiser A, Selhub J, Jacques PF, Rosenberg IH, D'Agostino RB, Wilson PWF, Wolf PA. Plasma homocysteine as a risk factor for dementia and Alzheimer's disease. N Engl J Med. 2002;346:476-83. https://doi.org/10. 1056/NEJMoa011613.

Shahrokhian S. Lead phthalocyanine as a selective carrier for preparation of a cysteine-selective electrode. Anal Chem. 2001;73:5972-8. https://doi.org/ $10.1021 /$ ac010541m.

Townsend DM, Tew KD, Tapiero H. The importance of glutathione in human disease. Biomed Pharmacother. 2003;57:145-55. https://doi.org/10.1016/ S0753-3322(03)00043-X.

Virji S, Kaner RB, Weiller BH. Hydrazine detection by polyaniline using fluorinated alcohol additives. Chem Mater. 2005;17:1256-60. https://doi.org/ 10.1021/cm0484091.

Wu CC, Zheng CM, Lin YF, et al. Role of homocysteine in end-stage renal disease. Clin Biochem. 2012;45:1286-94. https://doi.org/10.1016/j.clinb iochem.2012.05.031.

Wu J, Pan J, Ye Z, Zeng L, Su D. A smart fluorescent probe for discriminative detection of hydrazine and bisulfite from different emission channels. Sens Actuators B Chem. 2018;274:274-84. https://doi.org/10.1016/j.snb. 2018.07.161.

Xiong K, Huo F, Chao J, Zhang Y, Yin C. Colorimetric and NIR fluorescence probe with multiple binding sites for distinguishing detection of Cys/Hcy and GSH in vivo. Anal Chem. 2019;91(2):1472-8. https://doi.org/10.1021/ acs.analchem.8b04485.

Yeun JY. The role of homocysteine in end-stage renal disease. Semin Dial. 1998;11(2):95-101. https://doi.org/10.1111/j.1525-139X.1998.tb00309.X.

Yin GX, Niu TT, Gan YB, Yu T, Yin P, Chen HM, Zhang YY, Li HT, Yao SZ. A multisignal fluorescent probe with multiple binding sites for simultaneous sensing of Cys. Hcy and GSH Angew Chem. 2018;57(18):4991-4. https:// doi.org/10.1002/anie.201800485.

Zelnick Sanford D, Mattie David R, Stepaniak PC. Occupational exposure to hydrazines: treatment of acute central nervous system toxicity. Aviat Space Environ Med. 2003;74:1285-91. https://doi.org/10.1080/10506 890701404354.

Zou Y, Li M, Xing Y, Duan T, Zhou X, Yu F. Bioimaging of glutathione with a twophoton fluorescent probeand its potential application for surgery guide in laryngeal cancer. ACS Sens. 2020;5:242-9. https://doi.org/10.1021/ acssensors.9b02118.

\section{Publisher's Note}

Springer Nature remains neutral with regard to jurisdictional claims in published maps and institutional affiliations.

\section{Submit your manuscript to a SpringerOpen ${ }^{\circ}$ journal and benefit from:}

- Convenient online submission

- Rigorous peer review

- Open access: articles freely available online

- High visibility within the field

- Retaining the copyright to your article

Submit your next manuscript at $\boldsymbol{\Delta}$ springeropen.com 